\section{JURNAL ABDIMAS

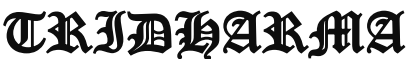

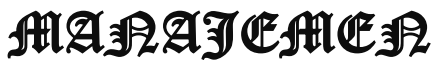

\title{
PENDAMPINGAN DAN PENYELENGGARAAN PEMBUATAN KEMASAN KERIPIK BUAH AGAR MENJADI DAYA TARIK KONSUMEN
}

\author{
Sam Cay, Sigit Purnomo, Dewi Sartika, Sri Sukapti \\ Dosen Manajemen Fakultas Ekonomi Universitas Pamulang \\ Email: dosen02207@unpam.ac.id
}

\begin{abstract}
ABSTRAK
Tujuan dari Kegiatan Pengabdian Kepada Masyarakat adalah untuk melaksanakan salahsatu Tri Dharma Perguruan Tinggi Universitas Pamulang. Selain itu diharapkan dengan pengabdian kepada masyarakat ini keberadaan perguruan tinggi dapat memberikan kontribusi besar kepada pengembangan dan penerapan keilmuan kepada masyarakat.

Metodekegiatan yang digunakanadalahkitamendatangi para pengusaha keripik buah yang beralamat di desa Santrean Malang, Jawa Timur danakanmemberikanpelatihandisana pada tanggal 11 sampai dengan tanggal 13 Mei 2019. Pelatihan ini bertujuan agar para pengusaha keripik buah yang berada di desa Santrean dapat meningkatkan penjualan mereka melalui inovasi dalam pengemasan keripik.

Hasil pengabdian kepada masyarakat yang diperoleh adalah bertambahnya keilmuan bagi para pengusaha keripik buah agar mereka memiliki pandangan yang baik tentang pentingnya menginovasi dan pengembangan dalam kemasan agar mampu bersaing dengan pengusaha lainnya yang sejenis, sehingga keterampilan yang diberikan mampu membantu para pengusaha dalam memenuhi keinginan konsumen.

Ilmu yang diperoleh pada pengabdi kepada masyarakat kali ini diharapkan mampu memberikan semangat baru bagi kita dalam menyampaikan materi dan motivasi serta berkontribusi bagi pengusaha UMKM baik dilingkungan pengusaha, kampus dan keluarga.
\end{abstract}

\section{Kata Kunci: Perencanaan Sumber Daya Manusia, Kemasan dan Pelanggan}

\section{ABSTRACT}

The purpose of Community Service Activities is to carry out one of the Tri Dharma College of Pamulang University. In addition, it is hoped that through community service, the existence of higher education institutions can make a major contribution to the development and application of knowledge to the community.

The method of activity used is that we go to the fruit chip entrepreneurs located in the village of Santrean Malang, East Java and will provide training there from 11 to 13 May 2019. This training aims to improve the fruit chip entrepreneurs in the village of Santrean to improve their sales through innovation in the packaging of chips. 


\section{JURNAL ABDIMAS

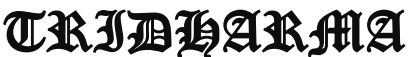

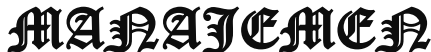

P-ISSN 2615-6849, E-ISSN 2622-3686

Jurnal ABDIMAS Vol. 1,No.1, Agustus 2019,Hal(127-133)

@Prodi Manajemen Fakultas Ekonomi Universitas Pamulang

Email: abdimasjurnal.unpam@ gmail.com Telp: (021) 741-2566

The results of community service obtained are increased knowledge for entrepreneurs of fruit chips so that they have a good view of the importance of innovating and developing in packaging to be able to compete with other similar entrepreneurs, so that the skills provided are able to help entrepreneurs in meeting consumer desires.

The knowledge gained in serving the community this time is expected to be able to provide new enthusiasm for us in delivering material and motivation as well as contributing to MSME entrepreneurs both within entrepreneurs, campuses and families.

\section{Keywords: Human Resource Planning, Packaging and Customers}

\section{PENDAHULUAN}

Keripik adalah salah satu makanan yang banyak diminati oleh para pencinta cemilan atau makanan kecil. Banyak sekali varian keripik yang berkembang di daerah Malang dari keripik buah, keripik apel, keripik pisang, keripik nangka dan berbagai macam keripik yang terbuat dari olahan buah-buahan.

Dalam menghadapi para pesaing yang rata-rata semuanya menjual keripik di daerah malang khususnya desa Santrean Malang Jawa Timur, maka para pengusaha keripik berusaha mencari jalan atau solusi agar usaha keripik mereka mampu bersaing dengan pengusaha keripik lainnya, salah satu cara yaitu dengan membuat kemasan yang menarik sehingga konsumen sebelum mencicipi rasanya saja sudah tertarik melihat kemasannya dan berniat untuk membeli.

Untuk mendukung tercapainya sasaran diatas, kami para dosen Prodi Manajemen Universitas Pamulang ingin membekali pemahaman dan memberikan keterampilan dan pengetahuan mengenai bagaimana membuat kemasan yang semenarik mungkin sehingga dapat meningkatkan pendapatan para pengusaha yang berada di desa Santrean tersebut

\section{RUMUSAN MASALAH}

Dengan mempertimbangkan latar belakang yang telah diutarakan diatas kami berinisiatif untuk membentuk pengabdian kepada masyarakat bagi para pengusaha keripik buah yang berada di desa Santrean Malang khususnya yaitu dengan memberi pembekalan keterampilan dan pengetahuan kepada para pengusaha keripik buah agar mereka mampu meningkatkan pendapatan atau keuntungan.

\section{TUJUAN PELAKSANAAN}

1. Memberikan pengetahuan mengenai betapa pentingnya sebuah kemasan bagi pengusaha keripik buah.

2. Memberikan pengetahuan kemasan yang seperti apa yang mampu menarik konsumen.

3. Memberikan keterampilan pembuatan kemasan yang ramah lingkungan tapi mampu menarik konsumen dengan bentuk dan keunikan kemasan keripik tersebut. 


\section{JURNAL ABDIMAS

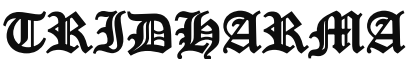

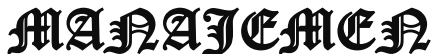

P-ISSN 2615-6849, E-ISSN 2622-3686

Jurnal ABDIMAS Vol. 1,No.1, Agustus 2019,Hal(127-133)

@Prodi Manajemen Fakultas Ekonomi Universitas Pamulang

Email: abdimasjurnal.unpam@ gmail.com Telp: (021) 741-2566

\section{TINJAUAN PUSTAKA}

\section{B. Perencanaan Sumber Daya Manusia}

Salah satu penjelasan mengenai Perencanaan Sumber daya manusia dapat diartikan perencanaan merupakan pengambilan keputusan tentang hal-hal yang akan dikerjakan saat ini untuk dikerjakan di masa depan dimana langkah-langkah tersebut diambil oleh organisasi guna mempersiapkan perencanaan strategis dimasa depan.

Menurut Sondang P. Siagian (2008: 41) mendefinisikan perencanaan sumber daya manusia sebagai langkah-langkah tertentu yang diambil oleh manajemen guna lebih menjamin bahwa organisasi tersedia tenaga kerja yang tepat untuk menduduki berbagai kedudukan, jabatan, dan pekerjaan yang tepat pada waktu yang tepat, semuanya dalam rangka mencapai tujuan dan berbagai sasaran yang telah ditetapkan. Sehingga dari definisi diatas tersebut, perencanaan sumber daya manusia memiliki manfaat, diantaranya ialah :

1. Perusahaan dapat memanfaatkan sumber daya manusia yang sudah ada dalam perusahaan secara lebih baik.

2. Memulai perencanaan sumber daya manusia dengan matang, produktivitas kerja dari tenaga kerja yang sudah ada dapat ditingkatkan.

3. Perencanaan sumber daya manusia berkaitan dengan penentuan kebutuhan akan tenaga kerja di masa depan.

4. Salah satu sumber informasi ketenaga kerjaan.
5. Penelitian yang dilakukan untuk kepentingan perencanaan sumber daya manusia.

6. Dasar bagi penyusunan program kerja yang menangani sumber daya manusia.

\section{Kemasan}

Saat ini kemasan dalam produk sangat diminati oleh pelanggan, dimana kemasan yang baik akan mudah menarik pelanggan atau konsumen untuk membeli produk tersebut, sehingga perusahaan perlu melakukan perubahan dalam mendisain sebuah kemasan untuk lebih menarik kembali. Biasanya fungsi utama dari kemasan adalah untuk menjaga produk. Kemasan yang dirancang dan di disain dengan kreatif dapat membangun ekuitas merek dan mendorong penjualan. Pengemasan suatu produk biasanya dilakukan oleh produsen untuk dapat merebut minat konsumen terhadap pembelian barang dan memberikan kesan yang baik dari produk tersebut. Menurut Kolter dan Keller (2009: 27), pengemasan adalah kegiatan merancang dan memproduksi wadah atau bungkus sebagai sebuah produk. Menurut Kotler sendiri terdapat empat fungsi kemasan sebagai satu alat pemasaran, yaitu :

\section{Self service}

Kemasan semakin berfungsi lebih banyak lagi dalam proses penjualan dimana kemasan harus menarik, menyebutkan ciri-ciri produk, menyakinkan konsumen dan memberikan kesan menyeluruh yang mendukung produk.

2. Consumer offluence

Konsumen bersedia membayar lebih mahal lagi dari ketergantungan dan prestise dari kemasan yang lebih baik. 


\section{JURNAL ABDIMAS

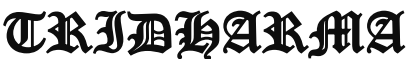

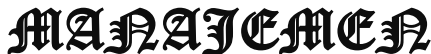

3. Company and Brand image

Perusahaan mengenal baik kekuatan yang dikandung dari kemasan yang dirancang dengan cermat dalam mempercepat konsumen mengenali merek produk.

4. Information transmission

Informasi tentang cara menggunakan transportasi, daur ulang, atau membuang paket produk yang sering terdapat pada kemasan atau label.

5. Reducting theft

Kemasan yang tidak dapat ditutup kembali atau akan rusak secara fisik (menunjukan tandatanda pembukaan) sangat membantu dalam pencegahan pencurian.

6. Convenience

Fitur yang menambah kenyamanan dalam distribusi, penanganan, penjualan, tampilan, pembukaan, kembali penutup.

7. Marketing

Kemasan dan label dapat digunakan oleh pemasar untuk mendorong calon pembeli untuk membeli produk.

\section{Pelanggan}

Seseorang atau sekelompok orang yang melakukan pembelian suatu produk dan melakukan interaksi pada waktu tertentu untuk memenuhi kebutuhan baik satu produk dan pengunalangan produk dapat diartikan sebagai pelanggan. Menurut Greenberg (2010), pelanggan adalah seseorang individu atau kelompok yang membeli suatu produk fisik dan jasa dengan mempertimbangkan berbagai macam faktor seperti harga, kualitas, tempat, pelayanan, dan lain sebagainya berdasarkan keputusan mereka sendiri. Masih menurut Greenberg, ada beberapa jenis pelanggan diantaranya:

1. Pelanggan internal

Sekelompok orang atau individu yang bertempat atau berlokasi dalam perusahaan dan umumnya memiliki andil atau pengaruh pada kinerja perusahaan.

2. Pelanggan antara

Sekelompok orang yang berada diantara produk namun bukan pemakai terakhir dari produk perusahaan .

3. Pelanggan eksternal

Sekelompok orang yang berada diluar perusahaan dengan menerima produk dari perusahaan.

\section{METODE PELAKSANAAN}

Metode kegiatan yang digunakan adalah dengan melakukan kunjungan langsung ke pengusaha keripik buah yang beralamatdi desa Santrean Malang Jawa Tmur, dan memberikan pelatihan disana pada tanggal $11 \mathrm{Mei}$ 2019 sampai dengan 13 Mei 2019. Pelatihan ini bertujuan agar para pengusaha keripik buah mampu bersaing dengan pengusaha yang lain melalui pembuatan kemasan keripik agar menarik konsumen.

Sebelum melaksanakan kegiatan pengabdian kepada masyarakat di desa Santrean Malang, Jawa Timur semua tim yang berjumlah 5 melakukan beberapa tahapan, melalui pra surview kelokasi untuk berkordinasi dengan lurah setempat dan mengunjungi petani buah, selanjutnya tim membuat 


\section{JURNAL ABDIMAS

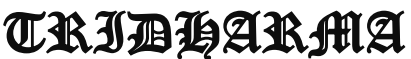

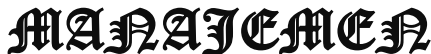

P-ISSN 2615-6849, E-ISSN 2622-3686

Jurnal ABDIMAS Vol. 1,No.1, Agustus 2019,Hal(127-133)

@Prodi Manajemen Fakultas Ekonomi Universitas Pamulang

Email: abdimasjurnal.unpam@gmail.com Telp: (021) 741-2566 penjadwalan kegiatan selama 3 (tiga) hari kedepan dengan membagi-bagi tugas termasuk pembuatan materi agar dapat diterima dan diaplikasi oleh petani buah setempat termasuk pendampingan, sampai terakhir pembuatan laporan kegiatan pengabdian kepada masyarakat serta pengajuan keluaran dari kegiatan pengabdian masyarkat berupa jurnal PKM.

\section{HASIL DAN PEMBAHASAN}

Pelaksanaan kegiatan Pengabdian Kepada Masyarakat oleh Lembaga Penelitian dan Pengabdian Masyarakat (LPPM) Universitas Pamulang yang dilakukan oleh dosen-dosen program studi Manajemen telah berjalan dengan lancar dan mendapat sambutan hangat dari tempat pelaksanaan kegiatan ini yaitu para Pengusaha Keripik Buah di desa Santrean Malang, Jawa Timur.

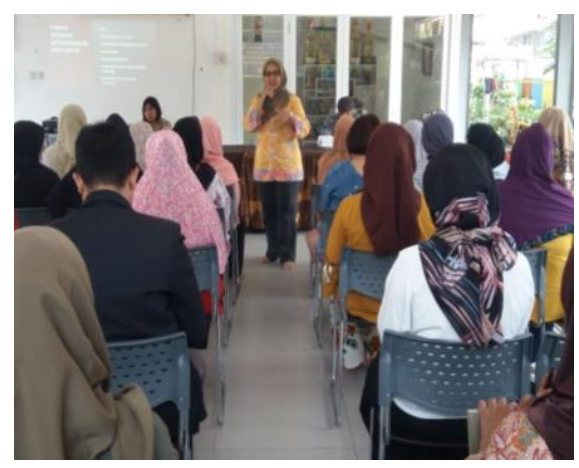

Harapan kami r dengan
pengabdian ini dapat membuka
wawasan para petani dan pengusaha
dapat meningkatkan mutu sumber daya
manusianya dengan membuat
perencanaan sdm yang baik, sehigga
strategi usaha dapat diukur baik jangka
pendek, menengah dan panjang. keripik
buah agar lebih kreatif dan Inovatif
dalam memasarkan produk mereka agar lebih menarik sehingga dapat menarik konsumen untuk membeli produk keripik tersebut. Sehingga kemasan yang dirancang dan di disain dengan kreatif dapat membangun ekuitas merek dan mendorong penjualan

Dalam laporan kegiatan ini mungkin banyak kekurangan yang ada, untuk itu kami berharap masukan dan kritikan dalam rangka perbaikan untuk kegiatan-kegiatan pengabdian masyarakat dimasa yang akan datang. Semoga kegiatan pengabdian masyarakat ini dapat bermanfaat bagi masyarakat sekitar lingkungan Malang khususnya untuk para Pengusaha Keripik Buah yang berada di Desa Santrean Malang, Jawa Timur.

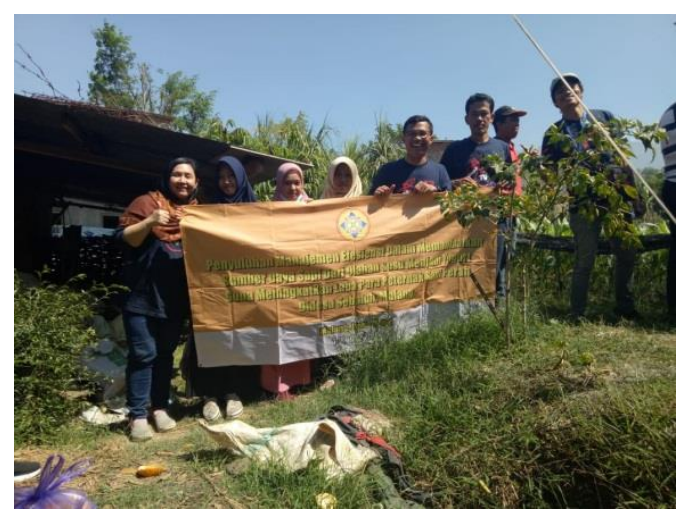

\section{KESIMPULAN DAN SARAN}

\section{A. Kesimpulan}

Dari hasil kegiatan pengabdian kepada masyarakat di desa Santrean Malang Jawa Timur, masih banyak petani buah yang juga sebagai pengusaha kripik buah belum memahami konsep dari manajemen dan aplikasi dari fungsi manajemen dengan baik sehingga cara mereka bekerja masih berdasarkan atas kondisi yang ada sehingga tidak tertata dengan baik yang menyebabkan hasil yang diperoleh tidak efektif dan efisien. 


\section{JURNAL ABDIMAS

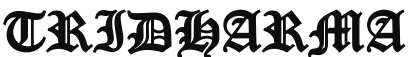

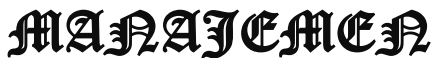

P-ISSN 2615-6849, E-ISSN 2622-3686

Jurnal ABDIMAS Vol. 1,No.1, Agustus 2019,Hal(127-133)

@ Prodi Manajemen Fakultas Ekonomi Universitas Pamulang

Email: abdimasjurnal.unpam@ gmail.com Telp: (021) 741-2566
Terutama dari pengelolaan hasil produksi seperti pengemasan (packing) yang masih dibuat secara sederhana yang menyebabkan kemasan tidak menarik dan terkesan asal-asalan. Dampak dari kemasan yang kurang menarik menyebabkan pelanggan atau konsumen kurang melirik produk keripik buah yang dihasilkan.

Strategi pemasaran yang masih terkelola dengan sederhana, dimana produk yang dihasilkan masih dititip warung ke warung, belum dapat membuat saluran pemasaran yang baik dan pemanfaatan teknologi digital marketing yang masih rendah.

\section{B. Saran}

Setelah kegiatan pengabdian kepada masyarakat ini berakhir baik dari pelatihan dan pendampingan diharapkan para petani dan pengusaha keripik buah di desa Santrean, Malang, Jawa Timur dapat meningkatkan hasil produktivitasnya sehingga produk yang dihasilkan dapat menjadikan keunggulan desa tersebut dan makin dikenal diwilayah malang secara khusus dan Indonesia secara umum, sehingga ada peningkatan pendapatan baik secara perorangan dan pendapatan daerah setempat. Sehingga kami sebagai tim pengabdi dari Universitas Pamulang Fakultas Ekonomi akan terus melakukan kegiatan serupa dan terkelanjutan serta berkesinambungan untuk membangun bangsa ini menjadi lebih baik.

\section{DAFTAR PUSTAKA}

Greenberg, Paul. 2010. "CRM at The Speed Of light: Social CRM 2.0 Strategies, Tools, and Techniques for Engaging Your Customer", New York : MCGraw Hill.

James A.F. Stoner, 2009.

Manajemen Jilid 1, terj. Alexander Sindoro, Jakarta: PT Prahallind.

Kotler, dan Keller. 2009.

"Manajemen Pemasaran". Edisi 12. Jakarta: Erlangga.

PASARIBU, V. L. D. (2017).

ANALISIS PENGARUH PROMOSI, KUALITAS PRODUK DAN DESAIN KEMASAN TERHADAP PERSEPSI MEREK YANG BERDAMPAK KEPADA KEPUTUSAN PEMBELIAN HAND AND BODY LOTION MEREK VASELINE (Studi Kasus TIP TOP Ciputat, Tangerang Selatan). INOVASI, 4(2).

PASARIBU, V. L. D. (2017). ANALISIS PENGARUH PROMOSI, KUALITAS PRODUK DAN DESAIN KEMASAN TERHADAP PERSEPSI MEREK YANG BERDAMPAK KEPADA KEPUTUSAN PEMBELIAN HAND AND BODY LOTION MEREK VASELINE (Studi Kasus TIP TOP Ciputat, Tangerang Selatan). INOVASI, 4(2).

Pasaribu, V. L. D., Susanti, F., \& Hartuti, E. T. K. (2019). MEMOTIVASI SISWA DAN SISWI SMK LETRIS INDONESIA DI DALAM 


\title{
JURNAL ABDIMAS P-ISSN 2615-6849, E-ISSN 2622-3686

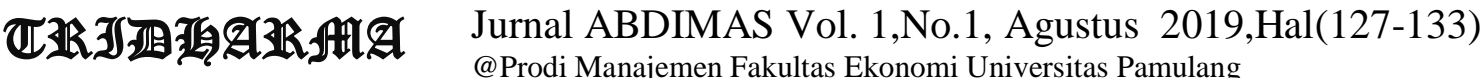

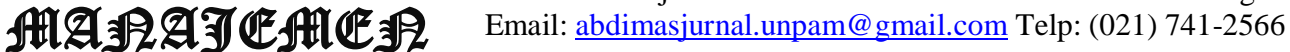

\author{
MENENTUKAN PILIHAN \\ UNTUK MELANJUTKAN \\ PENDIDIKAN ATAU BEKERJA \\ SETELAH LULUS \\ SEKOLAH. Jurnal Pengabdian \\ Dharma Laksana, 1(2), 161-172.
}

Siagian, Sondang P. 2008.

"Manajemen Sumber Daya

Manusia". Bumi Aksara Jakarta.

T. Hani Handoko, 2010,

Manajemen Personalia dan Sumber daya manusia" Edisi kedua, BPFE, Yogyakarta. 